RODRIGUES, Sónia Valente; Silva, Fátima; Carvalho, Ângela; Fardilha, Luís; Santos, Paulo Jorge - O potencial formativo das fundamentações pedagógico-didáticas nas práticas reflexivas dos professores em formação inicial: contributo para o seu estudo. A linguística na Formação do Professor: das teorias às praticas. Porto: Universidade do Porto. Faculdade de Letras, 2019. p. 163-180 DOI: https://doi.org/10.21747/978-989-8969-20-0/linga10

SÓNIA VALENTE RODRIGUES, FACULDADE DE LETRAS DA UNIVERSIDADE DO PORTO / CENTRO DE LINGUÍSTICA DA UNIVERSIDADE DO PORTO

FÁTIMA SILVA, FACULDADE DE LETRAS DA UNIVERSIDADE DO PORTO / CENTRO DE LINGUÍSTICA DA UNIVERSIDADE DO PORTO

ÂNGELA CARVALHO, FACULDADE DE LETRAS DA UNIVERSIDADE DO PORTO / CENTRO DE LINGUÍSTICA DA UNIVERSIDADE DO PORTO

LUÍS FARDILHA, FACULDADE DE LETRAS DA UNIVERSIDADE DO PORTO / CENTRO DE INVESTIGAÇÃO TRANSDISCIPLINAR "CULTURA, ESPAÇO E MEMÓRIA"

PAULO JORGE SANTOS, FACULDADE DE LETRAS DA UNIVERSIDADE DO PORTO / CENTRO DE PSICOLOGIA DA UNIVERSIDADE DO PORTO

\title{
O POTENCIAL FORMATIVO DAS FUNDAMENTAÇÕES PEDAGÓGICO- DIDÁTICAS NAS PRÁTICAS REFLEXIVAS DOS PROFESSORES EM FORMAÇÃO INICIAL: CONTRIBUTO PARA O SEU ESTUDO
}

RESUMO: O presente artigo, com enfoque na escrita para desenvolvimento da consciência e conhecimento profissional explícito, tem por objetivo apresentar os resultados de uma investigação centrada na análise de fundamentações pedagógico-didáticas produzidas por professores de português em formação inicial para explicitarem os fundamentos em que assentam as decisões subjacentes ao processo de planificação de aulas. $\mathrm{O}$ corpus, constituído por 30 textos, foi submetido a uma análise de conteúdo temática com base em seis categorias. Os resultados apontam para uma prevalência de aspetos didáticos como as atividades e os materiais didáticos de suporte e uma ausência de referência à avaliação das aprendizagens, no processo de planificação de aulas. Em síntese, o estudo confirma o potencial da fundamentação pedagógico-didática como instrumento para aprofundamento profissional a partir da prática contextualizada e identifica áreas de melhoria para a sua utilização na formação inicial de professores.

PALAVRAS-CHAVE: formação de professores, professor reflexivo, escrita, fundamentação pedagógico-didática

ABSTRACT: This article, focused on writing for the development of professional awareness and professional explicit knowledge, aims to present the results of an investigation based on the analysis of the theoretical background of lesson plans (fundamentação pedagógico-didática) produced by Portuguese teachers in initial training. The purpose of these texts is to create a framework 
for lesson plans and justify the options assumed during their elaboration. The corpus comprises 30 texts, which were subjected to a thematic content analysis based on six categories. The results point to a prevalence in the planning process of didactic aspects, such as activities and supporting teaching materials, and an absence of learning assessment references. In sum, the potential of the theoretical background of lesson plans writing is confirmed as a tool for professional development from the contextualized practice and areas of improvement for its use in initial training are identified.

KEYWORDS: teachers training, reflective teacher, writing, theoretical background of lesson plans

\section{1 - Introdução}

O modelo de formação reflexivo de professores de línguas por que se rege a formação inicial de professores de línguas na Faculdade de Letras da Universidade do Porto (Almeida et al. 2016; Pazos Anido et al. 2017; Hurst 2018) integra diferentes estratégias de desenvolvimento de competências profissionais fundamentais para um professor. Do conjunto das competências profissionais do professor discutidas por vários especialistas, destacamos três, centrais na preparação dos professores para os múltiplos contextos educativos com que se deparam ao longo da vida: o saber-analisar, o saberrefletir e o saber-justificar-se (Altet 2001: 35). Altet cria uma correspondência entre as competências de que os professores necessitam na prática para fazerem face aos diferentes contextos educativos e as competências a desenvolver ao longo do processo de formação, articulando deste modo a teoria (formação) com a prática (experiência profissional ou exercício da profissão). A figura 1 representa essa correspondência.

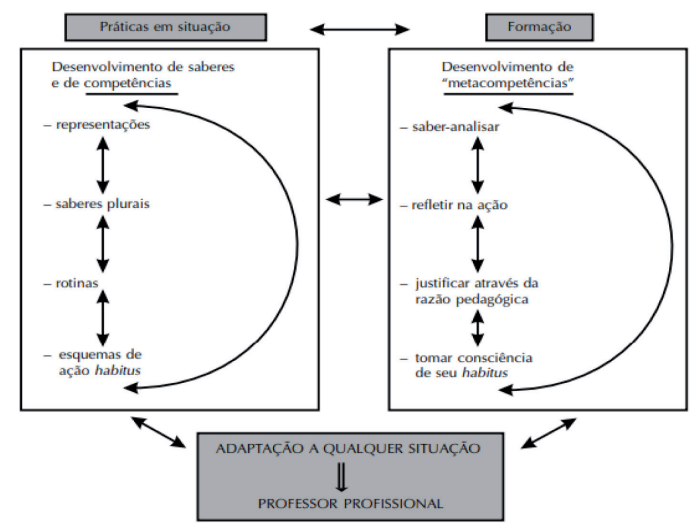

Figura 1 - Desenvolvimento de competências do professor reflexivo (Altet 2001: 35) 
No âmbito da formação inicial de professores de línguas, em particular durante o estágio pedagógico, os estudantes encontram-se perante a necessidade de, entre outras atividades, observar, analisar, planificar, realizar e avaliar aulas. Essas atividades obrigam ao desenvolvimento de saberes, procedimentos e atitudes que implicam «nomear e interpretar as práticas e as situações, ao racionalizar os conhecimentos pedagógicos que se transformam em conhecimentos da prática conscientizada» (Altet 2001: 33) e adquirir saberes e capacidades «para nomear, interpretar, distanciar-se das práticas, das situações, das interações pedagógicas, dos instrumentos de formalização e de apropriação da realidade produzidos pela pesquisa», «para explicitar os conhecimentos empíricos, a partir de confrontações a respeito de suas experiências» (Altet 2001: 33).

As aprendizagens decorrentes da formação inicial de professores são realizadas mediante diferentes discursos, sejam orais (comentário de aulas, reflexão em grupo, por exemplo), sejam escritos (diário de aula, planos de aula, reflexões escritas, entre outros).

No que diz respeito ao trabalho de planificação didática, uma das atividades discursivas usada como estratégia para o desenvolvimento das competências referidas (o saber-analisar, o saber-refletir e o saberjustificar-se) consiste na produção escrita de um texto de fundamentação pedagógico-didática (FP) das decisões subjacentes a um plano de aula (ou de dispositivos de aprendizagem).

Este estudo visa contribuir para a reflexão em torno do potencial formativo da fundamentação pedagógico-didática que os professores em formação inicial produzem no âmbito da planificação de sequências didáticas. $\mathrm{O}$ desenho da investigação realizada baseou-se na natureza discursiva e técnica da fundamentação pedagógico-didática e em duas questões subjacentes à sua utilização como estratégia de formação inicial de professores. Nas secções seguintes, explicitaremos estes dois tópicos.

\section{1 - Fundamentação pedagógico-didática}

A FP evidencia o conhecimento específico da organização e gestão do processo de ensino-aprendizagem que o professor em formação inicial mobiliza para explicar a planificação das aulas que irá realizar.

Embora haja vários estudos que apontam, de forma mais ou menos direta, para a sua produtividade na formação inicial de professores (Leite 2010; Pais 2010, 2013; Pereira 2012; Silva et al. 2015), falta comprovar empiricamente que a elaboração do texto de FP de uma sequência letiva contribui efetiva e positivamente para o desenvolvimento da consciência profissional (de natureza pedagógico-didática) dos futuros professores. 


\section{2 - Estudo}

O estudo constitui uma primeira etapa da investigação em curso, que tem por finalidade descrever a fundamentação pedagógico-didática enquanto texto de circulação restrita ao campo da formação inicial de professores de línguas associado a género textual específico (Silva et al. 2015). Esta primeira etapa é orientada por duas questões:

1. Que elementos da planificação letiva são mencionados nos textos de fundamentação pedagógico-didática?

2. Que elementos da planificação letiva são objeto de fundamentação pedagógico-didática?

No sentido de responder a estas duas questões, foi desenhada uma investigação centrada na análise de fundamentações pedagógico-didáticas e guiada pelos seguintes objetivos:

i. identificar os elementos da planificação letiva mencionados na FP;

ii. identificar os elementos da planificação letiva que são objeto de fundamentação.

\section{2 - Metodologia}

\section{1 - Corpus}

A amostra analisada é constituída por 30 fundamentações pedagógicas produzidas por estudantes durante o estágio pedagógico do curso de Mestrado em Ensino de Português Língua Segunda/Língua Estrangeira, da Faculdade de Letras da Universidade do Porto (FLUP). Na constituição do corpus foram tidos em consideração dois critérios: o da diversidade de estudantes e o facto de os seus estágios pedagógicos serem orientados por professores diferentes (estudantes com, pelo menos, três orientadores de estágio diferentes) e terem sido realizados em diferentes anos letivos (entre os anos letivos 2012 e 2017).

\section{2 - Análise de dados}

Num primeiro momento, procedeu-se manualmente a uma análise de conteúdo categorial (Bardin 2014: 38-39). Para isso, foram realizados três procedimentos:

i. o recorte de unidades de registo, que correspondem a "temas" ou "núcleos de sentido específicos" recorrentes nas FP analisadas (por exemplo, segmentos referentes a "objetivos da aula" ou a "materiais didáticos"); 
ii. a categorização das unidades de registo recortadas, a partir de uma codificação não exclusiva e emergente;

iii. a contabilização das ocorrências de expressões dentro de cada categoria de análise.

Num segundo momento, os dados obtidos foram sujeitos a uma análise quantitativa, que deu origem à interpretação dos textos, à luz dos objetivos definidos.

\subsection{1 - Categorias de análise}

As categorias de análise, definidas em função da literatura, da observação de aulas e de uma leitura prévia dos elementos de análise, são as seguintes ${ }^{1}$ :
A. objetivos;
B. temas;
C. momentos da aula;
D. ações de ensino e atividades;
E. avaliação;
F. materiais/recursos didáticos.

\section{A. Objetivos}

Relativamente à categoria $\mathrm{A}$, objetivos, foram considerados os enunciados em que está expresso o resultado em termos de aprendizagem (conhecimentos, capacidades, atitudes, valores, competências) a adquirir pelo aluno após uma determinada prática pedagógica ${ }^{2}$ e os que explicitam o propósito ou finalidade da sequência didática e/ou das aulas. Por razões que se prendem com a fundamentação de decisões relacionadas com outros elementos específicos da planificação (retomados mais adiante), não foram integrados nesta categoria os enunciados que explicam as estratégias, as atividades e os materiais através da menção dos resultados de aprendizagem a obter. Estes enunciados particulares ocuparão outra categoria devido à função argumentativa que desempenham.

Os excertos (1) e (2) ilustram os dois tipos de contexto em que ocorre a explicitação dos objetivos: o primeiro refere a finalidade da unidade didática, enquanto o segundo tem como escopo os resultados de aprendizagem a adquirir depois da prática de atividades para alargamento de conhecimentos culturais do domínio do futebol.

\footnotetext{
${ }^{1}$ Dada a extensão e complexidade do material textual analisado, a lista das categorias de análise poderia ser mais vasta, incluindo, por exemplo, "conteúdos programáticos", "perfil da turma", "conceções de ensino", entre outras. Para este trabalho, optámos por apresentar apenas os dados de algumas das categorias emergentes.

${ }^{2}$ Os objetivos de aprendizagem consistem na «Specification of learning to be achieved upon completion of an educational programme or an activity. (Adapted from: UIS 2012). Learning objectives can also be specified for a lesson, a theme, a year, or an entire course.» (IBE Glossary of Curriculum Terminology, UNESCO, p. 36).
} 
(1) A criação desta unidade didática para alunos de português língua estrangeira/língua segunda, tem como principal objetivo a realização de atividades que permitam a estes aprendentes o desenvolvimento de competências de compreensão e expressão orais, compreensão da leitura, da expressão da escrita, do funcionamento da língua e da reflexão gramatical. (A_SA-01_Doc01) ${ }^{3}$

(2) Relativamente ao objetivo de alargar os conhecimentos culturais relativos ao tema do futebol, espera-se que os alunos sejam capazes de identificar clubes, figuras, expressões típicas e conceitos relacionados com o mundo do futebol português, assim como estabelecer relações entre o futebol e outros domínios, com destaque para o papel que desempenha na aproximação entre povos e culturas. (A_SE-41_Doc28)

\section{B. Temas}

A categoria B, temas ${ }^{4}$, agrega os enunciados em que se expressam as áreas da vida ou do mundo contemporâneo que constituem o contexto em que se poderão desenvolver as aprendizagens relacionadas com conhecimento, capacidades, atitudes e valores (por exemplo, os passatempos, a música, hábitos e tradições). No âmbito das fundamentações pedagógicas da planificação de sequências didáticas, os temas são indicados a partir das orientações programáticas correspondentes a cada nível (A.1, A.2, B.1, B.2, C1, C2), delimitados de acordo com os descritores de desempenho enunciados no QECR (2001) e no CEFR (2018).

Nos excertos (3) e (4), apresentam-se exemplos de, respetivamente, um tema nuclear de uma unidade didática e um tema selecionado para uma etapa específica dessa unidade, a segunda unidade letiva, e, que em certa medida, poderemos considerar como um subtema de um tema nuclear, dado que o tratamento da figura do Zé Povinho surge no contexto de um trabalho centrado sobre figuras da cultura popular.

(3) No que refere ao tema unificador da unidade didática, optarei pelo cinema português que servirá como elo entre as atividades propostas. Esta temática será repartida em duas unidades letivas de cento e vinte minutos. (B_SE-04_Doc19)

(4) A escolha do tema para a segunda aula recai sobre uma figura incontornável do panorama cultural português: o Zé Povinho. Criada por Bordalo Pinheiro em 1875, esta figura é um símbolo do povo português. Por este motivo, o nome de Bordalo Pinheiro esta intimamente ligado a caricatura portuguesa, a qual deu um grande impulso, imprimindo-lhe um estilo próprio que a levou a uma visibilidade nunca antes atingida. (B_SA-11_Doc12)

\footnotetext{
${ }^{3}$ A codificação dos segmentos discursivos segue a seguinte norma: dimensão - unidade de registo - FP em que ocorre. Assim, por exemplo, no caso de (1) e de (2), o código dos excertos tem, respetivamente, a seguinte leitura: categoria $\mathrm{A}$ - segmento argumentativo 01 - documento 01 ; categoria $\mathrm{A}$ - segmento expositivo 41 - documento 28 .

${ }^{4}$ «Inter-disciplinary knowledge is often framed under crosscutting "themes" in curricula, as areas of contemporary, real-life concern (e.g. environmental issues, migration issues, technological advancements) that provides an authentic context in which the learner develops relevant and meaningful knowledge and other competency domains (e.g. skills, attitudes and values) in an inter-disciplinary mode.» (OECD E2030 Working Language).
} 
A categoria $\mathrm{C}$, momentos de aula, traduz a consciência da estrutura da aula, organizada em torno de um fio lógico, com princípio, meio e fim. É visível em enunciados que explicitam uma organização sequencial de ações e procedimentos do professor, com especificação dos passos, fases ou etapas em que cada ação de ensino se desdobra.

Os excertos (5) e (6) exemplificam a verbalização desta categoria em duas FP.

(5) primeira aula desta segunda unidade didática começará com...; O momento da aula que se segue é...; Seguidamente os alunos terão que...; A última tarefa desta aula será...; A segunda aula começará com...; A seguinte tarefa da aula terá como base...; Como tarefa final desta aula...; A terceira aula iniciar-se-á com... (C_SE-02_Doc03)

(6) No início da aula, e como elemento de ligação à aula anterior, apresentei um acetato com um cartoon da Mafalda. (C_SA-02_Doc10)

\section{Ações de ensino e atividades}

A categoria $\mathrm{D}$, ações de ensino e atividades, agrega o conjunto das informações relacionadas com o modo como a aula foi construída com vista às aprendizagens esperadas por parte dos alunos. Nela foram tidos em conta aspetos como:

(i) tarefas e/ou atividades a realizar pelos alunos;

(ii) ações de ensino, estratégias, abordagens.

Os exemplos (7) e (8) exemplificam, respetivamente, cada um destes aspetos.

(7) Após responderem a um questionário de compreensão global do excerto, no qual deverão deduzir sentidos implícitos das falas das personagens, detetando marcas irónicas, proceder-se-á à descodificação de cinco expressões idiomáticas presentes no excerto. Para consolidação das aprendizagens feitas na aula anterior, seguir-se-ão dois exercícios relativos aos verbos introdutores de relato de discurso de complexificação crescente. No primeiro, os alunos deverão completar o relato de uma das personagens, em discurso indireto, com os verbos introdutores de relato de discurso mais adequados. No segundo, terão de redigir o relato, em discurso indireto, da intervenção de uma das personagens, feito por outra personagem, num contexto enunciativo pré-definido, utilizando verbos introdutores do relato do discurso complementados por expressões descritivas. (D_SE-09_Doc16)

(8) Quanto à estruturação da aula e organização das atividades, optei por recorrer o modelo de Gelabert, Benítez \& Bueso (2002: 39) para a exploração da oralidade, que surge abaixo adaptado:

1. Pré-atividades

- Atividade de motivação: exploração de uma imagem

- Atividades de antecipação do tema 
2. Pré-leitura

-visionamento de um vídeo

- atividades de reconhecimento do registo coloquial

- atividades de correspondência de expressões coloquiais e significado

3. Leitura

- ordenação do texto

- atividades de compreensão do texto

4. Pós-leitura

- audição de um programa radiofónico

- preenchimento de um texto lacunar

- atividades de trabalho linguístico- escolha múltipla

4.1. Dramatização de papéis. (D_SE-03_Doc05)

\section{E. Avaliação}

$\mathrm{Na}$ categoria $\mathrm{E}$, avaliação ${ }^{5}$, são considerados os processos (análise documental, observação, testagem) e as estratégias (autoavaliação, heteroavaliação) usados para obter informação válida e fidedigna acerca dos resultados da aprendizagem realizada pelos alunos, tendo por base critérios qualitativos específicos. Os elementos recolhidos, que permitem reconstituir o processo educativo e o progresso das aprendizagens, podem ser documentados através de meios diversificados (registos de observação, textos produzidos pelos alunos, testes, entre outros). Nesta categoria, preveem-se aspetos como: o objeto de avaliação (as aprendizagens que se esperavam dos alunos), as técnicas e os instrumentos de recolha de informação, a análise e interpretação dos dados.

Os excertos (9) e (10) atestam o modo como os professores em formação inicial textualizam as suas opções no que se refere à avaliação.

(9) No que diz respeito ao tipo de avaliação, todas as atividades dos alunos serão avaliadas através da observação direta e da correção, em conjunto do que fizeram no tempo de aula e tanto é válido para a oralidade como para a escrita. Os trabalhos de casa da primeira unidade letiva serão levados para correção e entregues de novo aos alunos. (E_SE-03_ Doc04)

(10) Quanto a avaliação dos estudantes, a docente estagiária teve em linha de conta uma observação direta atenta e interventiva, apoiando o corpo discente ao longo do desenvolvimento das aulas e limando aspetos ou corrigindo erros quando necessário. Foram ainda solicitados, para além do trabalho produzido em cada aula, trabalhos de casa sempre em articulação e consonância com o tema abordado e desenvolvido e com os tópicos relevantes para cada unidade didática. Desses mesmos trabalhos efetuados pelos

\footnotetext{
5 O conceito de "avaliação" é aqui definido de acordo com a seguinte conceção: «The processes and strategies used to identify the achievements of a learner or learners in compliance with specific quality criteria. Assessment includes the conceptualization of learning processes and outcomes, their measurement and analysis, and the interpretation. » (OCDE, Glossary; Adapted from UNESCO-IBE Glossary)
} 
estudantes foi dado feedback aos alunos, tendo também sido aconselhados tópicos de pesquisa para realizarem, querendo, posteriormente, e a acrescentar à formação iniciada e desenvolvida no espaço destas quatro unidades letivas. (E_SE-04_Doc07)

\section{F. Materiais/recursos didáticos}

Finalmente, a categoria $\mathrm{F}$, materiais/recursos didáticos ${ }^{6}$, inclui todos os recursos que constituem o suporte para que o processo de aprendizagem decorra de modo a que os alunos construam o conhecimento, desenvolvam capacidades, atitudes e valores, e ponham em prática as competências que se prevê que obtenham. Para tal, os materiais ou recursos utilizados pelos professores são de natureza diversificada, podendo contemplar subcategorias como: (i) livros, manuais escolares, portefólios; (ii) meios audiovisuais como vídeos, multimédia; (iii) textos/discursos (notícias, documentários, reportagens, canções, narrativas, diálogos, anúncios publicitários, requerimentos, e.o.); (iv) questionários pedagógicos escritos e/ ou orais, fichas de trabalho (orientadas para a oralidade, a leitura, a escrita, a gramática), guiões de visionamento; (v) materiais digitais de aprendizagem autodidata, dicionários em linha.

Nos exemplos (11) e (12), são apresentados excertos das FP em que esta categoria é mobilizada. Enquanto em (11) se faz a síntese dos materiais e recursos didáticos utilizados numa dada unidade didática, com duas unidades letivas, com a apresentação do princípio subjacente à sua seleção, dado na $1^{\text {a }}$ frase do excerto, em (12) há igualmente referência ao tipo de material selecionado. Em ambos os excertos, há a focalização da seleção no designado 'material autêntico', com especificação de subcategorias. Assim, são elencados materiais das três subcategorias acima mencionadas: (i) manuais ilustrados; (ii) anúncios publicitários, extrato de um filme, vídeo; (iii) revistas portuguesas, mapa de Portugal, desdobráveis; (iv) fichas de trabalho em suporte de papel.

(11) Os materiais a serem utilizados em aula de PLE têm de ser atrativos e diversificados por forma a potenciarem resultados e a serem melhor acolhidos pelo público aprendente, independentemente da faixa etária do mesmo. Assim, para a primeira e a segunda regências

\footnotetext{
${ }^{6} \mathrm{Na}$ base da categoria “materiais” está a seguinte definição: «Los materiales curriculares, también denominados didácticos, son recursos de distinto tipo - impresos como los libros de texto, audiovisuales como un vídeo, multimedia como un DVD, etc.- que se emplean para facilitar el proceso de aprendizaje. Constituyen un componente más del currículo, por lo que se requiere que mantengan una coherencia con el resto de elementos curriculares, esto es, con los objetivos, contenidos, metodología y evaluación de la enseñanza-aprendizaje. (...) La elaboración de materiales curriculares se concibe, por tanto, en función de diversos factores: los objetivos de aprendizaje, las necesidades de los alumnos, los procesos mentales que se quieren fortalecer o el medio social en que se utilizan. En consecuencia, no puede hablarse de materiales didácticos buenos ni malos a priori, sino de materiales más o menos adecuados a la propuesta docente que se persigue desarrollar.» (Centro Virtual Cervantes, Diccionario de términos clave de ELE, em linha, disponível em: https://cvc.cervantes.es/ Ensenanza/Biblioteca_Ele/diccio_ele/indice.htm)
} 
foram escolhidos materiais diversificados, como o recurso a anúncios publicitários na Internet, o visionamento do extrato de um filme português de Leonel Vieira, selecionados após uma reflexão contínua e séria sobre as actividades/estratégias de ensino/aprendizagem a serem desenvolvidas e implementadas nas aulas. Foi ainda utilizado material autêntico como: revistas portuguesas, mapa de Portugal e ainda fichas de trabalho diversificadas, em suporte de papel, para deteção da compreensão a vários níveis... (F_SA-27_Doc_07)

(12) De referir também que durante esta unidade letiva o público aprendente irá contactar com algum material autêntico, com o vídeo, desdobráveis/brochuras, manuais ilustrados sobre aspetos da Cultura/História Portuguesa... (F_SA-40_Doc_13)

Relativamente aos conceitos mencionados, importa referir que não foi feita uma distinção em função do escopo tido em consideração. Por exemplo, a indicação dos objetivos aparece por referência a dois planos: o da sequência didática (o conjunto de duas ou três aulas planeadas) e o da aula (equivalente a 120 minutos). O mesmo acontece com os temas: por vezes, é identificado o tema da unidade didática; outras vezes, a cada aula corresponde um tema. Independentemente da unidade recoberta pela categoria (objetivos, tema, etc.), aula ou sequência didática, os segmentos analisados foram integrados na categoria geral.

\subsection{2 - Análise}

A anotação do corpus foi, como referido, manual, realizada em quatro fases.

A primeira fase consistiu em analisar cada texto do corpus, identificando os segmentos associados a cada categoria. As unidades de registo recortadas integram enunciados de extensão muito variável: em alguns casos, são frases ou expressões que representam uma proposição assertiva; noutros, são sequências textuais maiores do que a frase; noutros ainda, são parágrafos ou até conjuntos de parágrafos, integrados numa mesma unidade de sentido. A segmentação do corpus não obedeceu, portanto, ao critério da extensão das unidades de registo, mas a uma lógica temática.

Numa segunda fase, as unidades de registo de cada categoria foram divididas em dois grupos, tendo por base a sua natureza predominantemente expositiva ou argumentativa. Considerámos, na primeira, os enunciados em que uma dada situação é referida sem uma justificação ou fundamentação explícita e, na segunda, os que contêm fundamentação pedagógico-didática explícita. Para esta divisão foram usados critérios linguísticos e discursivos associados à presença explícita de elementos e/ou expressões linguísticas que traduzem nexos de causalidade e/ou de consequência entre situações.

Os segmentos (13) e (14) correspondem, respetivamente, a um segmento expositivo (SE) e a um segmento argumentativo (SA). São ambos extraídos da categoria B - Temas, para que possamos ilustrar o que distingue um segmento meramente expositivo, em que se descreve uma opção tomada ou a sequenciação de uma ação de ensino de forma meramente assertiva, 
e o segmento argumentativo, que articula a enunciação de uma opção (a seleção do tema "cultura popular das Janeiras e Cantares dos Reis") com a explicitação dos princípios ou razões que a justificam (introduzidas pelos estruturadores textuais 'em primeiro lugar' e 'em segundo lugar', que prefaciam relações causais introduzidas, respetivamente, por "por ser uma manifestação popular..." e "devido à data da regência ser...")

(13) De entre os temas a lecionar neste nível, optou-se pela "Música Portuguesa", tendo como foco o Fado. (B_SE-03_Doc18)

(14) Sendo assim, e tendo-me proposto a trabalhar sobre a importância da canção na aula de português língua estrangeira (PLE), escolhi como tema da primeira unidade didática a cultura popular das Janeiras e Cantares dos Reis, em primeiro lugar por ser uma manifestação popular tipicamente portuguesa e, em segundo, devido à data da regência ser propícia à abordagem do tema: é a época em que se cantam as Janeiras e os Reis. (B_SA-03_Doc04)

Na terceira fase, procedemos à codificação de cada uma das unidades de registo. Os segmentos predominantemente expositivos foram identificados com o código SE seguido do número de ordem (SE 01, 02, 03, n...), os argumentativos com o código SA (SA $01,02,03, n . .$.$) . Este procedimento$ permitiu a contagem do número de unidades de registo correspondentes a cada categoria para ser possível identificar as dimensões da planificação didática mais representadas nas fundamentações pedagógicas e as que têm uma expressão mínima ou nula. Este exercício confrontou-nos com um problema específico: como proceder quando, numa unidade de registo, nos deparamos com uma justaposição de elementos? Um caso concreto relaciona-se com a indicação e justificação de uso de uma série de materiais didáticos: contabilizamos uma unidade de registo com 5 materiais referidos ou contabilizamos 5 unidades de registo? Foi necessária a resolução de questões deste tipo para garantir a fiabilidade e a validade da análise.

Importa referir que a terceira fase teve dois ciclos de análise. Houve um primeiro ciclo de recorte, divisão e codificação das unidades de registo, que gerou um conjunto vasto de segmentos a considerar na contagem de dados. Após este exercício, procedeu-se a uma revisão dos conceitos inerentes às categorias de análise e das respetivas definições, necessária para assegurar a coerência e a fiabilidade. Com base nesta revisão, abriu-se um segundo ciclo de análise, distanciado temporalmente do primeiro, que permitiu uma reflexão mais profunda sobre os critérios de recorte, divisão e codificação das unidades de registo. Foi esta última versão que alimentou a quarta fase da metodologia.

\footnotetext{
7 A análise pormenorizada destes dois tipos de segmentos está já em curso, prevendo-se a comunicação dos resultados dela decorrentes para publicação posterior a este artigo.
} 
A quarta fase consistiu na análise e interpretação dos dados obtidos.

\section{3 - Resultados}

\section{1 - Dados resultantes}

Os dados apresentados no gráfico 1 dizem respeito ao número de FP em que há referência a cada uma das categorias de análise.

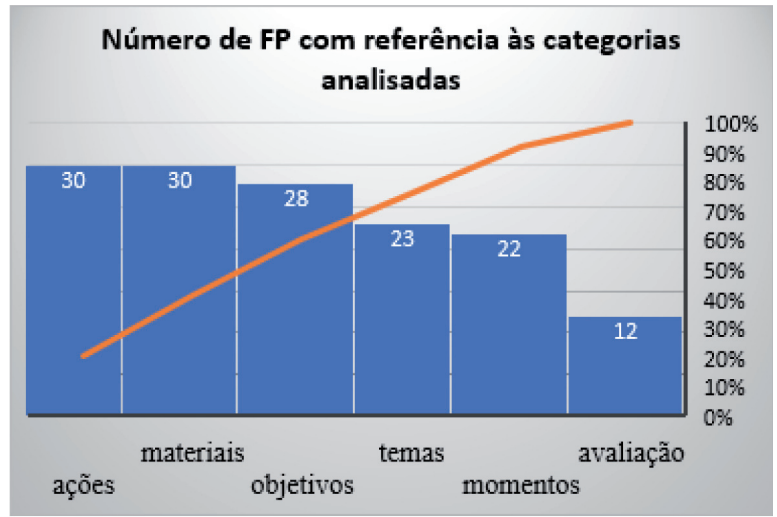

Gráfico 1 - FP com referência às categorias analisadas

Ao quantificar as unidades de registo por categoria e a distribuição dessas unidades de registo em segmentos expositivos e argumentativos, obtivemos os dados da tabela 1 .

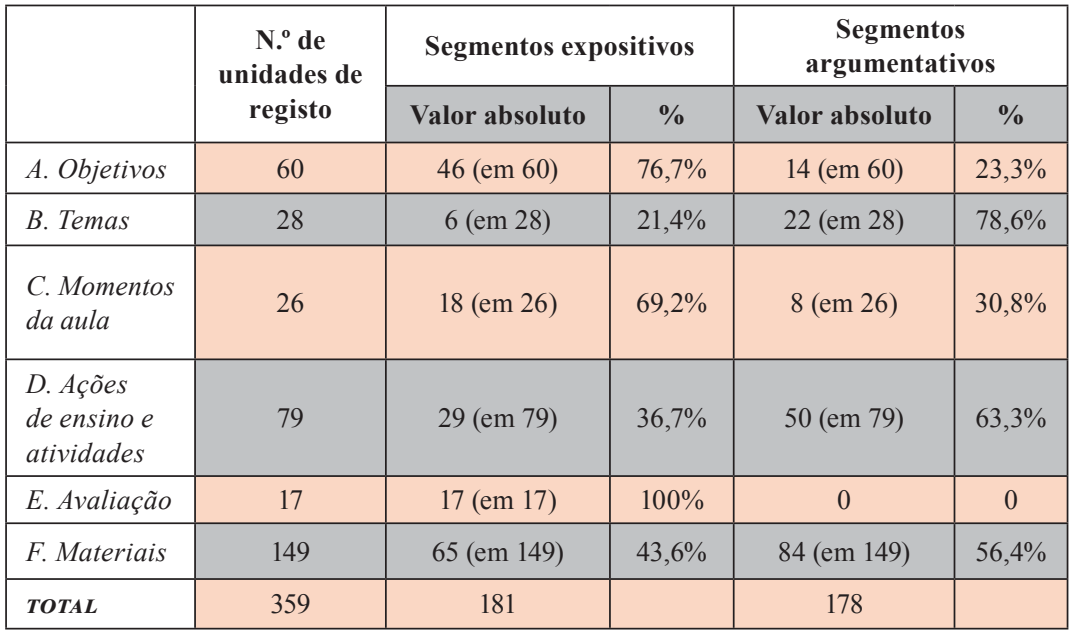

Tabela 1 - Dados quantitativos da análise por categorias 
Destes dados, é relevante para o estudo a comparação do número de unidades de registo em cada categoria. Como se vê no gráfico 2, existe uma variação significativa entre a categoria com menos unidades de registo (17, na avaliação) e aquela que apresenta o maior número (149, nos materiais).

\section{Número de unidades de registo por categoria}

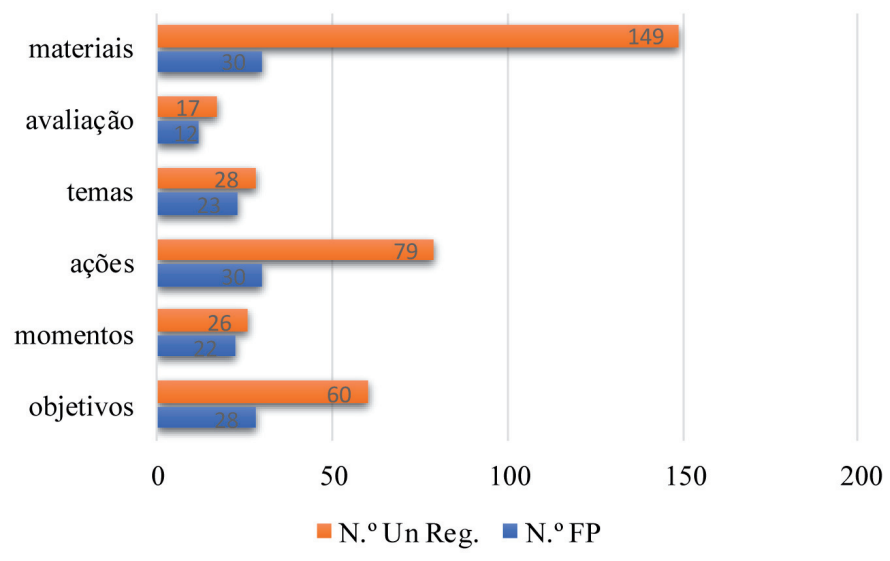

Gráfico 2 - Número de unidades de registo por categoria

Igualmente significativa é a variação existente, em cada categoria, entre o número de segmentos expositivos e argumentativos, como se pode confirmar pelo gráfico 3 .

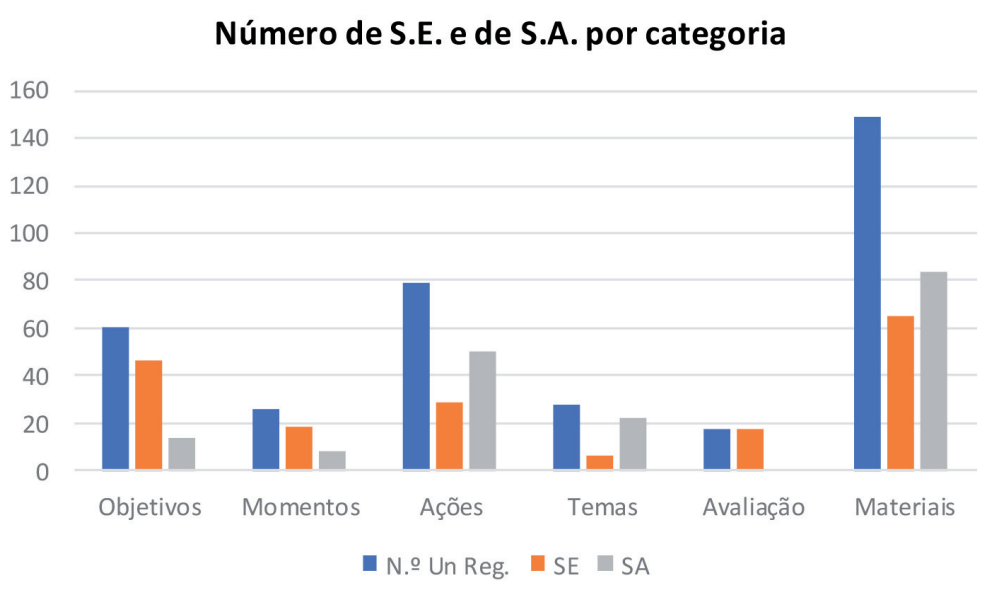

Gráfico 3 - Número de SE e de SA por categoria 


\section{2 - Discussão dos resultados}

Os dados autorizam algumas inferências relevantes para os objetivos traçados.

Em primeiro lugar, mostram que as FP são textos centrados sobretudo na apresentação e explicação ou justificação de ações de ensino e atividades e de materiais didáticos, se tivermos em conta o número de FP em que são referidas essas categorias (gráfico 1). Estes dados são consistentes com o número de unidades de registo por categoria. Neste domínio, são os materiais de ensino-aprendizagem a categoria que mais espaço textual ocupa nas FP (gráfico 2): as ações de ensino e atividades têm 79 unidades de registo em 30 FP; os materiais têm 149 unidades de registo em 30 FP. Quanto ao número de ocorrências das categorias no conjunto das FP, importa também referir os objetivos (propósito educativo e resultados de aprendizagem), que, embora menos expressiva do que as atividades e os materiais, revela uma elevada taxa de frequência. De facto, os objetivos são referidos em 28 FP (num total de 30), mas apresentam um elevado número de unidades de registo (60), o que significa que a sua referência ocorre mais do que uma vez em cada texto como elemento de base para a escolha de atividades, de temas, de materiais da aula.

Os temas e os momentos de aula são categorias presentes na maioria das FP. Já a avaliação é a categoria com menor expressão nas FP. Em 30 FP, apenas 12 contêm referência à avaliação das aprendizagens (o que pode mostrar que não existe uma integração clara da ação de avaliar enquanto procedimento de ensino-aprendizagem nem como dimensão formativa, talvez com base no pressuposto de que a avaliação dos alunos em que se dá a aula será função do orientador).

Em segundo lugar, as categorias em que se verifica um número de SA superior aos SE são as ações de ensino e atividades, os temas e os materiais/ recursos didáticos (o que pode revelar que são as dimensões em que maior liberdade de decisão é facultada ao estagiário, que está a lecionar em turmas que são de outros professores e, de algum modo, ajusta a ação docente que planifica ao esquema conceptual de aula do orientador). Destas três categorias em que há maior fundamentação, aquela que se destaca pelo número de referências é a dos materiais/recursos didáticos. Esta tendência pode mostrar a preocupação do estagiário relativamente à ação de planificar uma aula e de justificar perante o orientador os materiais que usa. Nos objetivos, nos momentos de aula e na avaliação, o número de SE é superior ao das SA, o que pode ser explicado pelo facto de serem dimensões da planificação que não estão no âmbito de decisão do estagiário, que assume os objetivos do QECR, esquemas metodológicos de autores citados e a avaliação do professor titular das turmas em que faz estágio. 
Tendo em conta a frequência das unidades de registo das três categorias com mais expressão, as FP mostram um núcleo central de texto fixado em elementos da planificação didática: os materiais/recursos didáticos, as ações de ensino e atividades e, logo de seguida, os objetivos e os temas. Este parece ser o foco dos estagiários no propósito de fundamentar (explicitar, explicar, justificar) as decisões pedagógico-didáticas das sequências de ensino.

O quadro interacional de produção da fundamentação pedagógicodidática, descrito em Silva et al. (2015), inscrito num modelo supervisivo em contexto de formação inicial de professores, poderá explicar a razão pela qual o conjunto de aspetos pedagógico-didáticos que o professor em estágio pedagógico assume como podendo fundamentar, por sentir que estão no seu âmbito de decisão e de relativa autonomia, são sobretudo as atividades e os materiais, que pesquisa, seleciona, adapta e constrói, e os temas e os objetivos, que seleciona a partir dos documentos orientadores do ensino-aprendizagem da língua. As referências à avaliação, por exemplo, em número significativamente residual, são o indício de que os estagiários não incorporam como estando no seu âmbito de atuação a avaliação das aprendizagens dos estudantes para quem preparam as aulas, considerando talvez ser essa uma responsabilidade do professor titular da turma.

Esta situação permite-nos equacionar a capacidade de intervenção do professor em estágio na planificação das aulas que leciona na turma de que o seu orientador de estágio é titular, por um lado, bem como da consciência relativa ao impacto das opções pedagógico-didáticas nas aprendizagens dos estudantes e à adequação dessas opções a determinados paradigmas ou quadros conceptuais de ensino das línguas.

No entanto, para que estas questões possam ser equacionadas, é necessário passar à segunda etapa desta investigação, que consiste em analisar os fundamentos pedagógico-didáticos convocados pelos professores em estágio para justificar as opções assumidas na planificação das aulas.

\section{4 - Considerações finais}

A análise realizada permitiu identificar as dimensões de aula consideradas como objeto de menção e de fundamentação nos textos produzidos pelos estudantes em estágio pedagógico.

Os resultados apontam para um conhecimento aceitável dos elementos constitutivos de uma planificação didática, embora seja significativa a quase ausência de menção a aspetos relacionados com a avaliação das aprendizagens programadas. Ficamos, assim, a compreender a consciência que os estudantes em formação inicial de professores revelam sobre as dimensões de aula sujeitas a decisão pedagógico-didática devidamente fundamentada. Revelam ainda a frequência com que os estudantes em 
estágio pedagógico-didático ativam conhecimento teórico (ou conhecimento resultante de investigação em didática das línguas) como fundamento para a prática letiva.

Tendo em conta o saber-analisar, o saber-refletir e o saber-justificar através de razão pedagógica (Altet 2001) como competências a desenvolver ao longo do processo de formação, de modo a articular teoria (formação) e prática (experiência profissional ou exercício da profissão), e considerando a fundamentação pedagógico-didática como estratégia ao serviço do desenvolvimento dessas competências, os resultados obtidos permitem:

- confirmar o potencial formativo da FP como estratégia de escrita ao serviço da análise, da reflexão e da justificação de elementos essenciais da planificação didática;

- detetar fragilidades quanto à mobilização de conhecimento oriundo da investigação em didática das línguas e em áreas direta ou indiretamente relevantes para os objetivos da(s) aula(s) a realizar;

- verificar a não consideração de princípios amplos de conceção de aula (por exemplo, a opção por um paradigma cognitivista-comunicativo em detrimento do paradigma transmissivo ou vice-versa).

Para que a fundamentação pedagógico-didática atinja o seu pleno potencial formativo, importa repensar o processo de construção textual e discursivo, o que poderá fazer considerar a implementação de uma oficina de escrita para aprofundamento profissional a partir da prática contextualizada.

\section{REFERÊNCIAS}

Almeida, J. D.; Ellsion, M.; Pazos Anido, M.; Barros Lorenzo, M.; Hurst, N.; Santos, P.; Nicolás, P.; Tomé, S.; Rodrigues, S. V. 2016. Orientações gerais para a elaboração do Relatório de Estágio em ensino de Português e de Lingua Estrangeira. Porto: FLUP.

Altet, M. 2001. As competências do professor profissional: entre conhecimentos, esquemas de ação e adaptação, saber analisar. In: L. Paquay; M. Altet; É. Charlier; P. Perrenoud (Org.). Formando professores profissionais. Quais estratégias? Quais competências? Porto Alegre: Artmed Editora, 23-35.

Bardin, L. 2014. Análise de conteúdo. Lisboa: Edições 70. Edição revista e atualizada.

Conselho da Europa. 2001. Quadro Europeu Comum de Referência para as Línguas. Porto: Asa.

Council of Europe. 2018. Common European Framework of Reference for Languages: Learning, Teaching, Assessment. Strasbourg: Council of 
Europe. Companion volume with new descriptors. Disponível em https:// rm.coe.int/cefr-companion-volume-with-new-descriptors-2018/1680787989. Acedido em 12-01-2019.

Hurst, N. 2018. Learning teaching: Research and reporting in the post-graduate language teaching practicum at the Faculty of Letters, the University of Porto, Portugal. In: A. Carvalho; J. D. Almeida; N. Hurst; R. P. de L. Romeo; S. der A. Tomé (Orgs.). As línguas estrangeiras no ensino superior: balanço, estratégias e desafios futuros. Porto: FLUP, 161-172.

Leite, T. 2010. Planeamento e concepção da acção de ensinar. Aveiro: Universidade de Aveiro.

Pais, A. 2010. Fundamentos didatológicos e técnico-didáticos de desenho de unidades didácticas para a área de Língua Portuguesa. In: Encontros de Didática. Covilhã: UBI, 1-18.

Pais, A. 2013. A unidade didática como instrumento e elemento integrador de desenvolvimento da competência leitora. Crítica da razão didática. In: F. Azevedo; M. da G. Sardinha (Eds.). Didática e práticas. A língua e a educação literária. Braga: Omnia Opera, 65-86.

Pazos Anido, M.; Rodrigues, S. V.; Tomé, S; Martínez, P. N.; Hurst, N.; Ellsion, M.; Lorenzo, M. B.; Silva, F.; Carvalho, A.; Almeida, J. D. 2017. Construção de um referencial de avaliação de desempenho do estudante de línguas em estágio pedagógico: problemas e desafios. Sensos-e. 4(1): 3-11.

Pereira, C. S.; Ribeiro, C. 2012. Supervisão pedagógica - Um alicerce para a construção do saber. Viseu: Universidade Católica Portuguesa.

Silva, F.; Rodrigues, S. V.; Carvalho, A. 2015. A fundamentação pedagógica como género de escrita na construção da profissionalidade docente. Redis: Revista de Estudos do Discurso. 4: 229-253.

UNESCO. 2013. IBE Glossary of Curriculum Terminology. Geneva: Unesco. Disponível em http://www.ibe.unesco.org/fileadmin/user_upload/ Publications/IBE_GlossaryCurriculumTerminology2013_eng.pdf. Acedido em 13/12/2018. 
